\author{
Damian Kowalczyk*, Mateusz Wach**, Albert Plewik**, \\ Slawomir Wysocki***
}

\title{
RELATIONSHIP BETWEEN THE RHEOLOGICAL PARAMETERS AND ZETA POTENTIAL OF BENTONITES****
}

\section{INTRODUCTION}

One of the most important elements of each drilling application is drilling fluid. Drilling mud fulfils a number of roles. First of all, it helps remove cuttings from borehole, maintains hydrostatic pressure against the borehole wall and seals it with a thin "wall cake". Drilling mud also lubricates and cools the drill bit. Of course, there is a difference between drilling fluids for HDD and vertical drilling. It is connected with significant differences arising from flow characteristics and physical dissimilarity borehole.

Bentonite is used as a base or starting point for drilling fluids. To control soil conditions additives and polymers are used. The main component of bentonite is montmorillonite. Different contributions of the mineral makes that not all bentonite clays may be used for drilling muds. Therefore, it is important to estimate the utility of bentonites in drilling fluids technology [1].

\section{ZETA POTENTIAL AND ELECTRIC DOUBLE LAYER}

Electrokinetic potential, also known as the zeta potential is a term connected with chemistry and physics. Defining the zeta potential requires knowledge of colloid chemistry. Zeta potential is a value describing the surface properties of solids dispersed in liquid. Zeta potential characterizes the interaction of colloid particles, determines the amount of electric charge in the immediate vicinity of the surface of a solid. The determination of the potential characterizes the behavior of bentonite particles in suspension, their interaction and stability of the suspension [2].

\footnotetext{
* CETCO-Poland CETCO Sp. z o.o. S.K.A

** AGH University of Science and Technology, Faculty of Drilling, Oil and Gas, Krakow, Poland - student

*** AGH University of Science and Technology, Faculty of Drilling, Oil and Gas, Krakow, Poland

**** The work realized within statutory research program of Faculty of Drilling, Oil and Gas, No. 11.11.190.555
} 
The development of a nett charge at the particle surface affects the distribution of ions in the surrounding interfacial region, resulting in an increased concentration of counter ions (ions of opposite charge to that of the particle) close to the surface. Thus, an electrical double layer exists around each particle. The liquid layer surrounding the particle exists as two parts; an inner region, called the Stern layer, where the ions are strongly bound and an outer, diffuse, region where they are less firmly attached. Within the diffuse layer there is a notional boundary inside which the ions and particles form a stable entity. When a particle moves ions within the boundary move with it, but any ions beyond the boundary do not travel with the particle. This boundary is called the surface of hydrodynamic shear or slipping planet. The potential that exists at this boundary is known as the Zeta potential (Fig. 1) [3].

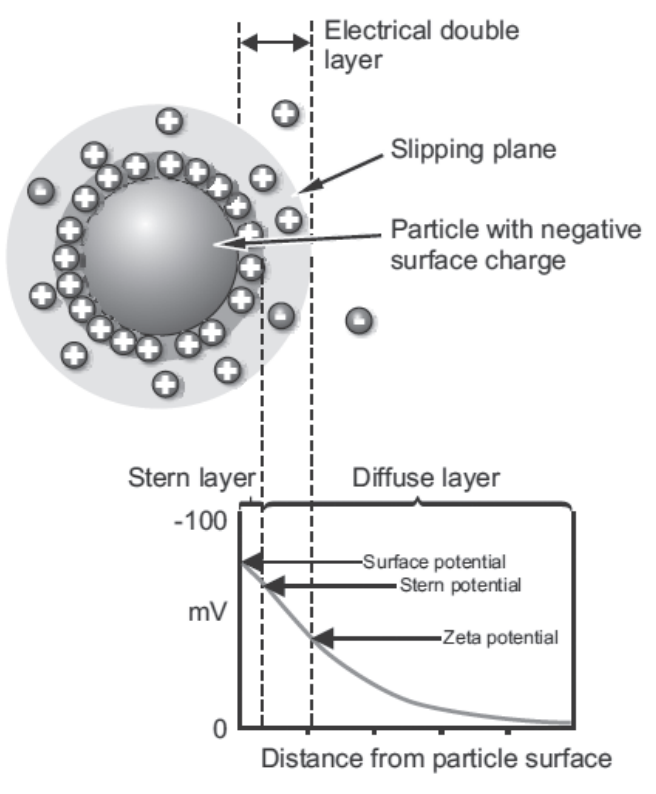

Fig. 1. Zeta potential and electrical double layer

For the purposes of the paper, Zeta potential was calculated by determining the Electrophoretic Mobility and then applying the Henry equation. The electrophoretic mobility is obtained by performing an electrophoresis experiment on the sample and measuring the velocity of the particles using Laser Doppler Velocimetry (LDV) [4].

The Henry equation is:

$$
U_{E}=\frac{2 \varepsilon \zeta f(k a)}{3 \eta}
$$

where:

$$
\begin{aligned}
\zeta & - \text { Zeta potential, } \\
U_{E} & - \text { Electrophoretic mobility, } \\
\varepsilon & - \text { Dielectric constant } \\
\eta & - \text { Viscosity } \\
f(k a) & - \text { Henry’s function. }
\end{aligned}
$$


If all the particles in suspension have a large negative or positive zeta potential, they will tend to repel each other and there is no tendency to aggregate. If the particles have low zeta potential values then there is no force to prevent the particles coming together and aggregating [5].

\section{LABORATORY RESEARCH}

For the purposes of the laboratory research, bentonite materials from CETCO-POLAND company were used. Rheological parameters tests have been done on the basis of API standards spec. 13A for the 3\% bentonite suspensions. Studies have been completed with a full rotation speed range with $0.1 \mathrm{rpm}$ and $0.036 \mathrm{rpm}$ (Low Shear Rate Viscosity). Furthermore, gel strengths and LSYP (Low Shear Yield Point) were designated (Tab. 1, Fig. 2-7).

Table 1

Research results of rheological parameters and zeta potential values

\begin{tabular}{|c|c|c|c|c|c|c|}
\hline & BCPD1 & BCPD2 & BCPG1 & BCPG2 & ВCPY2 & CPW14 \\
\hline 600 & 2.8 & 19.6 & 3 & 9.2 & 26 & 27 \\
\hline 300 & 1.7 & 17.5 & 1.7 & 5.3 & 22 & 19 \\
\hline 200 & 1.4 & 17.7 & 1.2 & 3.8 & 19.9 & 16 \\
\hline 100 & 0.8 & 14.8 & 0.6 & 2.3 & 17 & 11.7 \\
\hline 60 & 0.5 & 13.8 & 0.4 & 1.9 & 15.9 & 10 \\
\hline 30 & 0.4 & 12.9 & 0.3 & 1.3 & 14.8 & 8.7 \\
\hline 20 & 0.3 & 12.7 & 0.3 & 1.2 & 14.6 & 8.4 \\
\hline 10 & 0.2 & 12.5 & 0.2 & 0.9 & 14.3 & 8.1 \\
\hline 6 & 0.2 & 12.6 & 0.2 & 0.8 & 14.2 & 8 \\
\hline 3 & 0.2 & 12.5 & 0.2 & 0.7 & 14.1 & 7.9 \\
\hline 2 & 0.2 & 12.6 & 0.2 & 0.7 & 14.1 & 7.9 \\
\hline 1 & 0.2 & 12.7 & 0.2 & 0.6 & 14.2 & 8 \\
\hline $0.1[\mathrm{mPa} \cdot \mathrm{s}]$ & 510.9 & 37,200 & 515.5 & 1,580 & $41,700.8$ & 24,740 \\
\hline $0.036(\mathrm{LSRV})[\mathrm{mPa} \cdot \mathrm{s}]$ & $1,318.8$ & $107,780.4$ & $1,394.1$ & 6,691 & 121,750 & 75,460 \\
\hline $0.1[\mathrm{mPa} \cdot \mathrm{s}]$ & 0.213 & 8.094 & 0.320 & 0.320 & 12.993 & 8.201 \\
\hline $0.036(\mathrm{LSRV})[\mathrm{mPa} \cdot \mathrm{s}]$ & 0.320 & 33.015 & 0.320 & 7.242 & 31.950 & 24.495 \\
\hline $\mathrm{PV}[\mathrm{mPa} \cdot \mathrm{s}]$ & 1.1 & 2.1 & 1.3 & 3.9 & 4 & 8 \\
\hline $\mathrm{AV}[\mathrm{mPa} \cdot \mathrm{s}]$ & 1.4 & 9.8 & 1.5 & 4.6 & 13 & 13.5 \\
\hline $\mathrm{YP}[\mathrm{lb} / 100 \mathrm{sq} \mathrm{ft}]$ & 0.639 & 16.401 & 0.426 & 1.491 & 19.17 & 11.715 \\
\hline LSYP [1b/100 sq ft] & 0.213 & 13.206 & 0.213 & 0.639 & 14.91 & 8.307 \\
\hline LSYP/YP & 0.333 & 0.805 & 0.500 & 0.429 & 0.778 & 0.709 \\
\hline $3 / 600$ & 0.071 & 0.638 & 0.067 & 0.076 & 0.542 & 0.293 \\
\hline Filtrate Volume $[\mathrm{ml}]$ & 42.34 & 11.21 & 42.51 & 16.51 & 11.06 & 10.91 \\
\hline Moisture [\%] & 12.25 & 12.12 & 13.32 & 12.84 & 12.89 & 9.37 \\
\hline $\mathrm{pH}$ & 8.13 & 9.99 & 8.28 & 9.63 & 9.26 & 8.86 \\
\hline Zeta potential $[\mathrm{mV}]$ & -14.5 & -46.9 & -23.6 & -32.9 & -36.8 & -38.6 \\
\hline
\end{tabular}




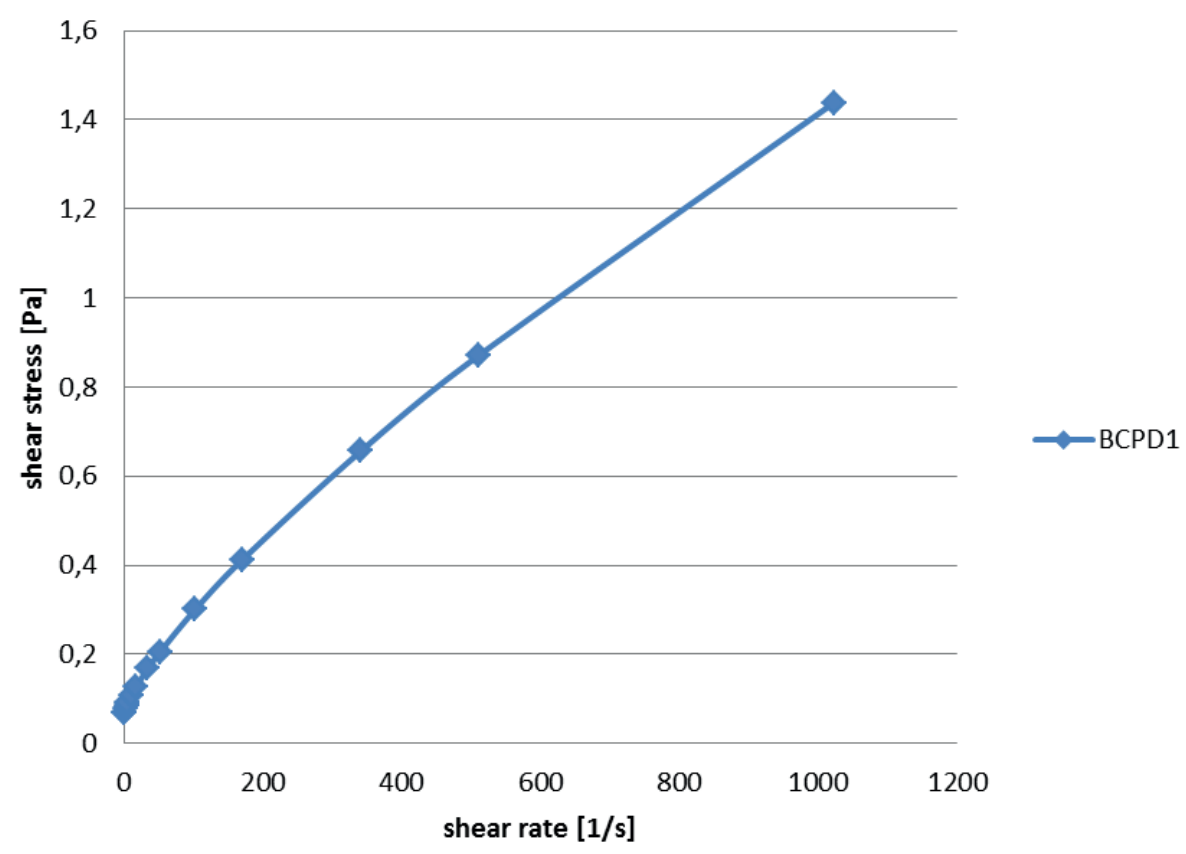

Fig. 2. The flow curve of the suspension prepared from a sample of BCPD1 based on Table 1 approximated by Herschel-Bulkley model

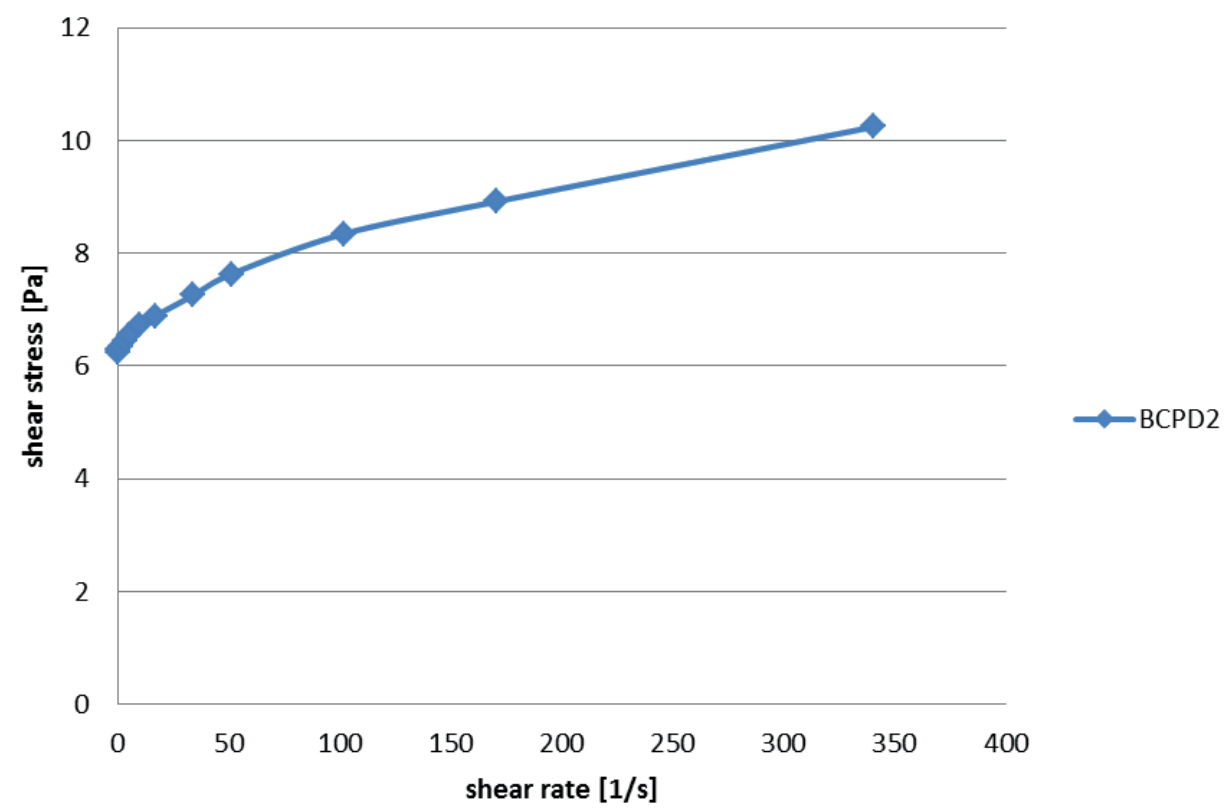

Fig. 3. The flow curve of the suspension prepared from a sample of BCPD2 based on Table 1 approximated by Herschel-Bulkley model 


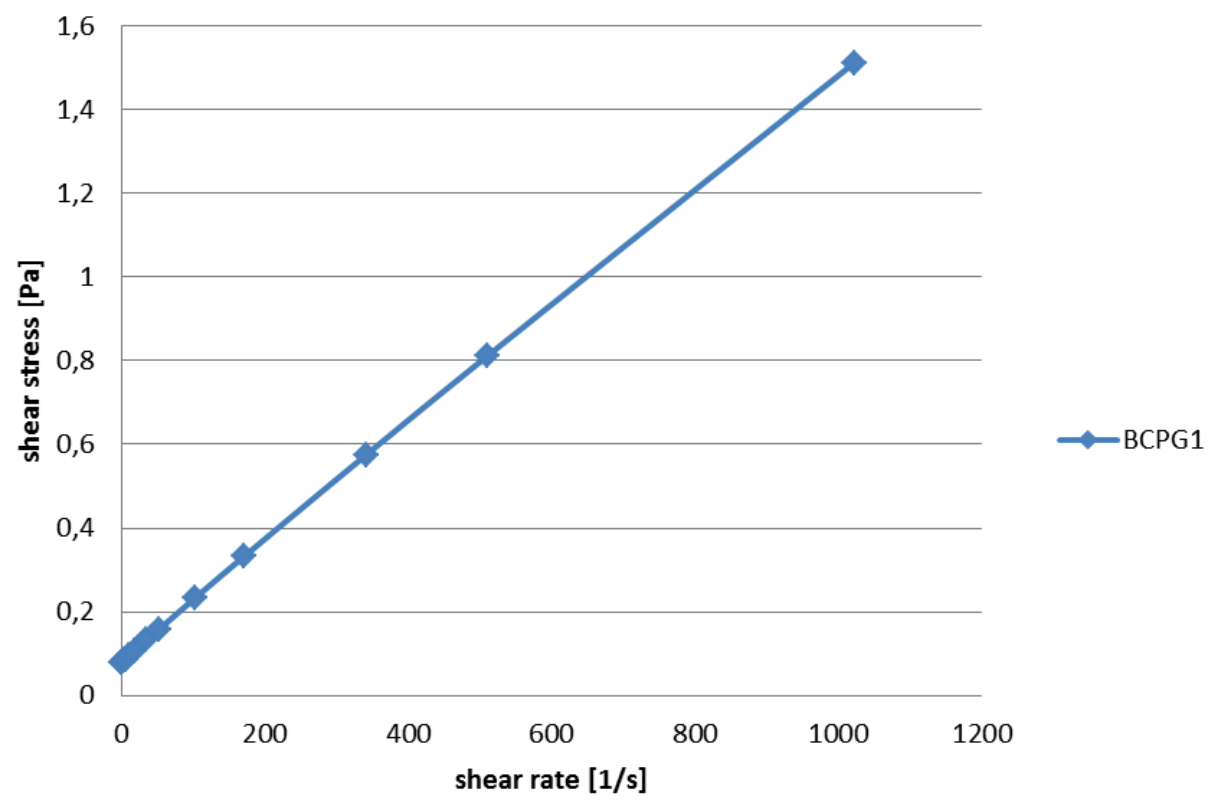

Fig. 4. The flow curve of the suspension prepared from a sample of BCPG1 based on Table 1 approximated by Herschel-Bulkley model

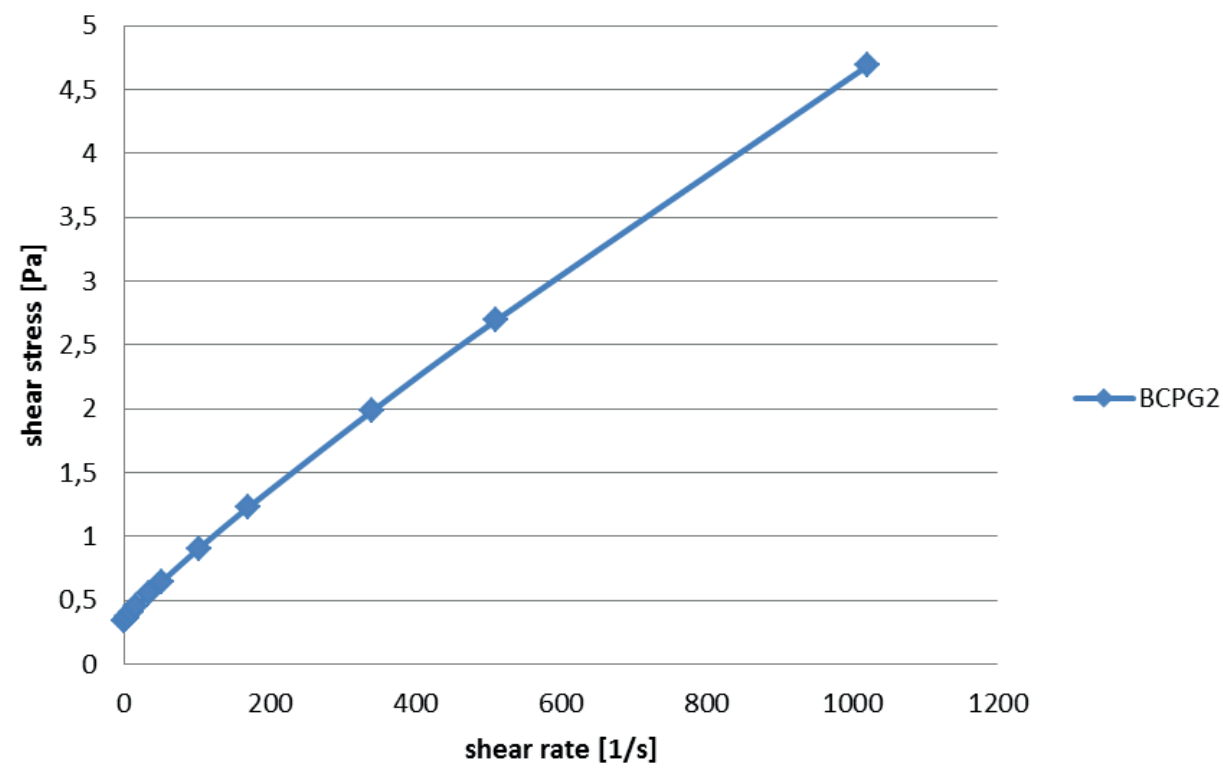

Fig. 5. The flow curve of the suspension prepared from a sample of BCPG2 based on Table 1 approximated by Herschel-Bulkley model 


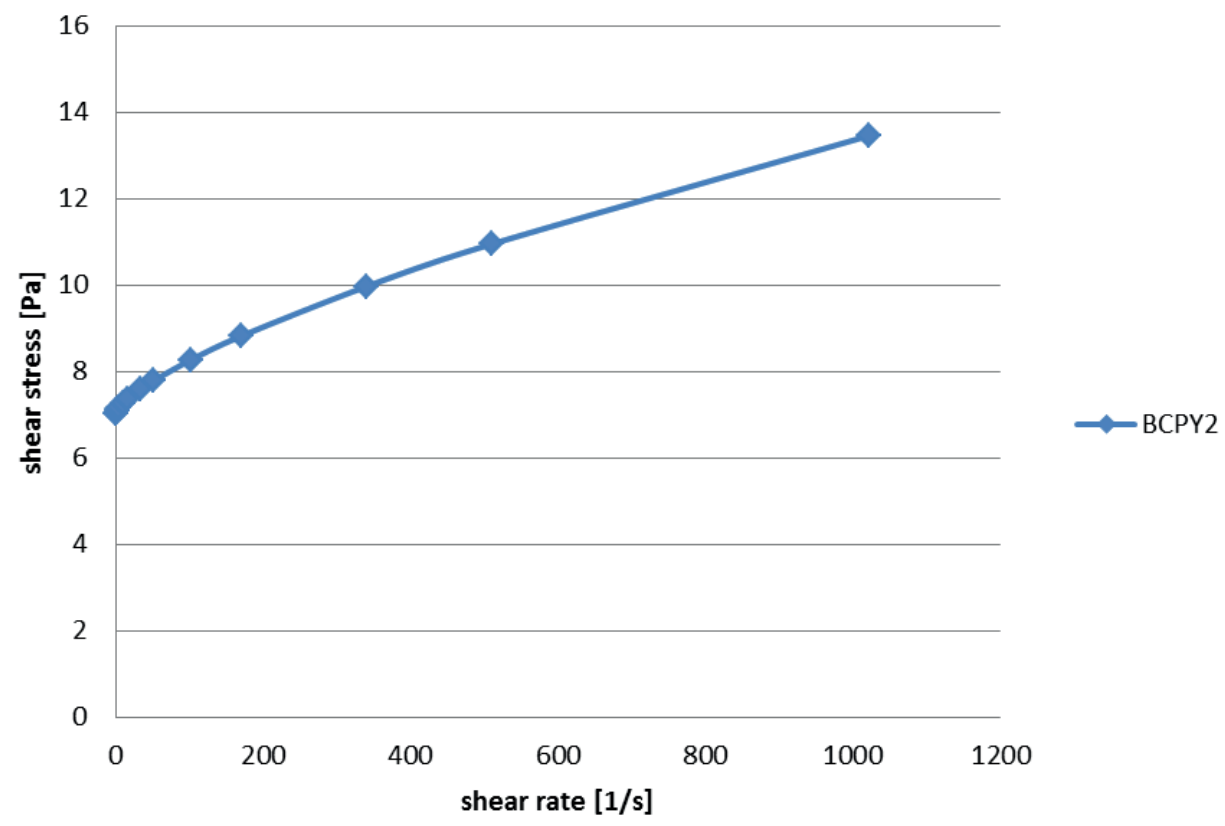

Fig. 6. The flow curve of the suspension prepared from a sample of BCPY 2 based on Table 1 approximated by the Herschel-Bulkley model

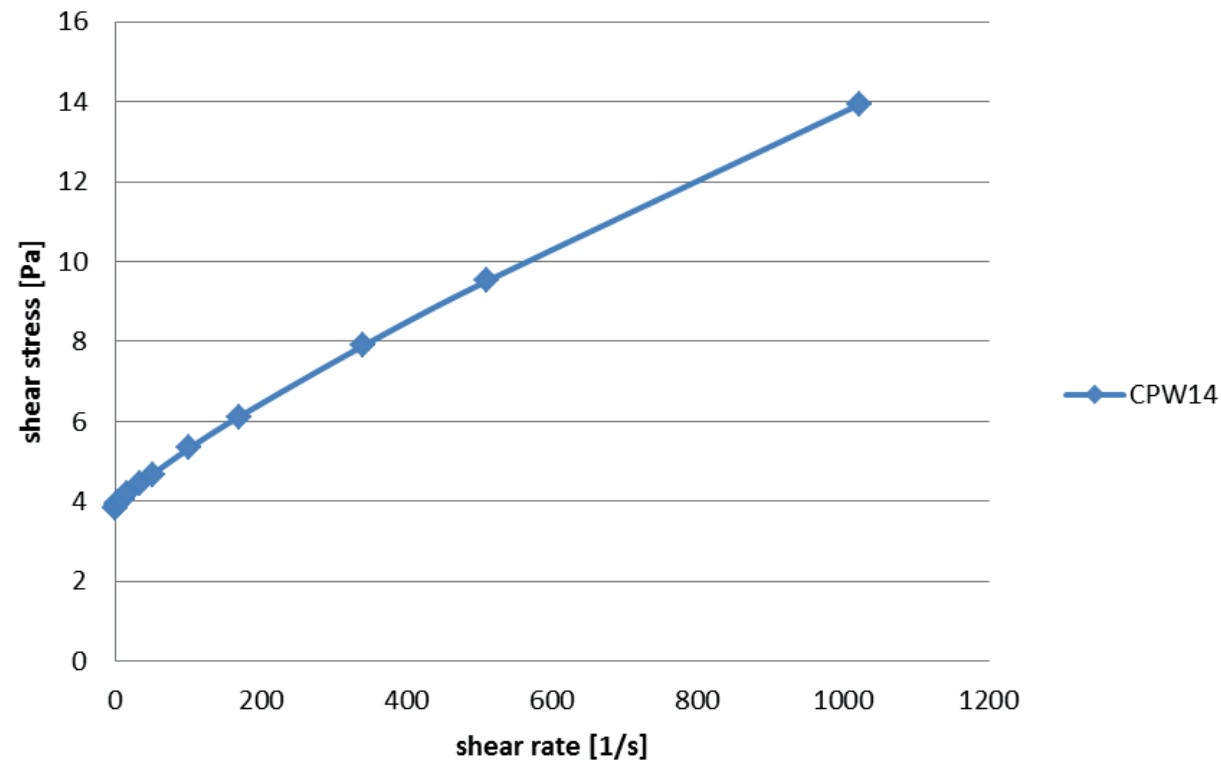

Fig. 7. The flow curve of the suspension prepared from a sample of CPW14 based on Table 1 approximated by the Herschel-Bulkley model 


\section{RESEARCH ANALYSIS AND CONCLUSION}

The tested clay materials are characterized by great diversity. The most flat flow curves describe BCPD2 (Fig. 3) and BCPY2 (Fig. 6). For these materials shear stresses change at least relative to shear rate. The $3 / 600$ parameter, describing the change in stress relative to shear rate, well characterizes changes in viscosity of the drilling fluid. This parameter for BCPD2 and BCPY2 is the highest and oscillates around 0.6. Both of these samples have a high viscosity at a low shear rate. Also the LSYP value is the highest and the ratio LSYP/ YP exceeds 0.8 . The highest structural strength is BCPY2, and the structural strength after the $10 \mathrm{~s}$. BCPD2 sample is relatively low in comparison with the gelling after 10 minutes. BCPD1, BCPG1 and BCPG2 are characterized by the lowest values of the aforementioned parameters, and their flow curves are almost straight lines. When it comes to viscosity, both the plastic viscosity and the apparent, highest is the material CPW14, while the lowest values have BCPD1 and BCPG1. Other parameters, such as filtration are the most propitious for the suspension CPW14, BCPY2 and BCPD2. The filtrate volume for these samples was the lowest. In turn, filtrate volume suspensions BCPD1 and BCPG1 exceed $40 \mathrm{ml}$. Moistures of the samples are between $12-13 \%$ by weight, only for CPW14 is below $10 \%$.

The study shows that the tested samples of the clays have a negative electrokinetic potentials. This indicates that the surface of the clay particles have a negative charge. The test suspensions have weakly alkaline and alkaline $\mathrm{pH}$. The greatest absolute value of the zeta potential is characterized by BCPD2 (the most negative potential). BCPD2 suspension also exhibits the highest $\mathrm{pH}$ among all the tested materials. In turn, the least negative potential value has BCPD1 suspension, the $\mathrm{pH}$ of which is the lowest.

To sum up, electrokinetic potential analysis allows for the evaluation of the usefulness of bentonite. For high shear stresses, the relationship between viscosity and zeta potential is imperceptible but for low shear stresses the relationship is significant. The reason is, for high shear stresses friction forces play a key role and when they cease to act, when shear stress is very low, particle electrostatic attraction appears.

\section{REFERENCES}

[1] Bielewicz D.: Ptyny wiertnicze. Kraków 2009.

[2] Bielewicz D.: Wykorzystanie zjawisk elektrokinetycznych w technologii pluczek wiertniczych. Kraków 1992.

[3] Chilingar G.V., Haroun M.: Elektrokinetics for Petroleum and Environmental Engineers, Salem-New Jersey 2014.

[4] Zetasizer Nano Series User Manual, Issue 1.1, Feb. 2004.

[5] Nowacka M.: Charakterystyka elektrokinetyczna i stabilność dyspersji wybranych układów tlenkowych. Poznań 2013. 